\title{
Neonatal Adaptation: Sympatho-Adrenal Response to Umbilical Cord Cutting
}

\author{
JAMES F. PADBURY, ${ }^{(34)}$ EMMANUEL S. DIAKOMANOLIS, CALVIN J. HOBEL, ALVIN PERELMAN, \\ AND DELBERT A. FISHER \\ Department of Pediatrics, Harbor-UCLA Medical Center, UCLA School of Medicine, Torrance, California, USA
}

\begin{abstract}
Summary
The present studies were designed to assess the individual effects of delivery and umbilical cord cutting on the stimulation of the sympatho-adrenal system during parturition. Pregnant ewes with time-dated singleton pregnancies were used in an acutely exteriorized fetal lamb model with an intact umbilical circulation. We observed a minimal, transient elevation in plasma catecholamines (CAT) coincident with the operative procedures and delivery. Subsequent cord clamping was observed to evoke a rapid and marked increase of both norepinephrine and epinephrine (E), maximal at $5 \mathrm{~min}$ and persisting over the $4 \mathrm{hr}$ study period. Animals could be grouped on the basis of the observed CAT responses, severity of postpartum acidosis, the extent of free fatty acid (FFA) mobilization and degree of postpartum hypothermia. A blunted FFA response and slower correction of hypothermia were observed in the more acidotic animals despite higher CAT concentrations. One group of four animals had high peak CAT concentrations, $32,000 \mathrm{pg} / \mathrm{ml}$ norepinephrine and $35,000 \mathrm{pg} / \mathrm{ml} \mathrm{E}$, a deep nadir in pH of $6.88 \pm 0.09$, a 2-hr delay in maximal FFA mobilization and slower correction of hypothermia. The other group of four animals had peak norepinephrine of $2800 \mathrm{pg} / \mathrm{ml}$ and $\mathrm{E}$ of 1100 $\mathrm{pg} / \mathrm{ml}$, a nadir in $\mathrm{pH}$ of $7.09 \pm 0.08$, maximal plasma FFA concentration by $1 \mathrm{hr}$ after cord cutting and a higher nadir in body temperature 35.7 versus $32.5^{\circ} \mathrm{C}$. The results demonstrate that umbilical cord cutting itself is a potent stimulus for fetal CAT release and FFA mobilization. Acidosis is capable of markedly augmenting $E$ release in the mature fetus and obtunding chemical thermogenesis.
\end{abstract}

\section{Speculation}

The marked catecholamine surge evoked by umbilical cord cutting at the time of birth appears to be a major factor triggering the metabolic events facilitating adaptation to extrauterine life. The mechanism for the catecholamine release is uncertain. However, cardiovascular and chemoreceptor mediated activation of autonomic nervous system activity probably are involved. The separate contributions of increased postganglionic neurosympathetic activity and adrenal-medullary catecholamine release to neonatal adaptation should be explored further.

Previous work in a variety of animals (9) and man (15) suggests that the sympatho-adrenal system is relatively mature at term. Substantial catecholamine release has been observed in the near term fetal sheep in response to a variety of stimuli including hypoxia (8), maternal blood volume depletion (2), and maternal exercise (18). In the human newborn we and others $(13,21,23)$ have shown striking elevations of plasma catecholamine (CAT) in both umbilical blood samples and neonatal blood drawn in the first minutes and hours of life. In each of the studies reported to date there was a marked umbilical artery to umbilical vein CAT concentration difference suggesting a fetal origin for the cord plasma CAT. In an earlier study of plasma CAT in the fetal sheep before and during parturition we demonstrated basal circulating levels at greater than $90 \mathrm{hr}$ before delivery with a gradual rise beginning with the onset of labor and high peak levels just prior to delivery (12).

It has not been possible, however, to dissociate the contributions of labor, delivery, and umbilical cord cutting as stimuli for CAT release in the newborn. It is known that cord plasma CAT levels are similarly elevated in vaginally delivered and cesarean section delivered newborns suggesting that labor per se is not a primary stimulus to CAT release $(13,21)$. Cord cutting is of particular interest because of the variety of metabolic and cardiovascular changes that have been observed with severence of the umbilical circulation. With birth and cord cutting there is a sudden increase in systemic blood pressure, closure of fetal shunts and an increase in cardiac output and cardiac work (27). Similarly, a variety of metabolic events are stimulated including hepatic glucose output, free fatty acid mobilization, nonshivering (chemical) thermogenesis, and production of triiodothyronine by peripheral tissues. We and others have demonstrated the importance of umbilical cord cutting itself in the initiation of these metabolic events $(28,17)$.

The present studies were designed to assess the individual effects of delivery and umbilical cord cutting on the stimulation of the sympatho-adrenal system during parturition. The results indicate that umbilical cord cutting is an important stimulus for CAT release. The implications for the physiologic adaptations to extrauterine life are discussed.

\section{MATERIALS AND METHODS}

\section{ANIMAL PREPARATION}

Eight Rambouillet-Columbia cross-bred ewes with time-dated singleton pregnancies near term were used in all studies; mean gestational age was $144 \pm 2$ days. All ewes were acclimated to the laboratory environment prior to surgery. On the day before surgery, food (alfalfa pellets) was withheld but the ewe was allowed access to water. Animals were premedicated with xylazine followed by spinal or epidural anesthesia. The pregnant uterine horn was exposed through a midline abdominal incision and individual fetal parts were identified by palpation. The fetal hindlimb was delivered through a small uterine incision and the fetal dorsal hindlimb artery was catheterized with a polyethelene catheter of appropriate size passed to the level of the descending abdominal aorta. The animal was delivered onto the maternal abdomen shortly after catheterization. There was careful attention to avoid traction or trauma to the umbilical cord. The exteriorized cord was covered with warm saline gauze and the fetal head was covered immediately with a warm saline-filled glove. The umbilical vessels remained filled and pulsated normally. Body temperature was monitored with an indwelling rectal probe.

Blood samples for CAT, blood gases, and free fatty acid (FFA) measurements were drawn after catheterization, immediately after 
delivery and intermittently until the time of cord clamping. Designations of $-60,-45,-30,-15,-5$, and $0 \mathrm{~min}$ are referred to zero time as cord clamping. After $1 \mathrm{hr}$ of observation the umbilical cord was clamped, the saline-filled glove was removed and the animal was allowed to breathe spontaneously. Blood samples were subsequently obtained at $5,15,30,60,120,180$, and $240 \mathrm{~min}$. Four milliliters of blood were collected each time and after cord clamping all samples were replaced with fresh heparinized residual placental blood (1 unit/ml blood).

Plasma was separated, quick frozen in liquid nitrogen and stored at $-70^{\circ} \mathrm{C}$ until subsequent assay. Plasma norepinephrine (NE) and epinephrine (E) concentrations were determined in duplicate $50-\mu$ l aliquots of plasma using a modification of the single isotope radioenzymatic assay of Passon and Peuler (25) as modified by Johnson and Peuler (19). The sensitivity of the assay is 1 to $2 \mathrm{pg}$ for $\mathrm{NE}$ and $\mathrm{E}$.

Duplicate $100-\mu \mathrm{l}$ samples were assayed for FFA using the colorimetric microdetermination described by Soloni and Sardina (29). All blood gas measurements were conducted using 0.3-ml heparinized blood and a Radiometer blood gas analyzer with temperature corrected to $39^{\circ} \mathrm{C}$.

Statistical analysis was performed by two-way analysis of variance (ANOVA) for evaluation of differences between groups over the base line observation period and following umbilical cord cutting. Logarithmic transformation was applied to all hormone concentration data before statistical manipulation. CAT concentrations at each time point are expressed in text as geometric mean concentration, with $95 \%$ confidence limits of the mean in parentheses. In the figures, results are expressed as geometric mean ( \pm S.E.) and displayed on logarithmic scales. Other calculated parameters are expressed as mean \pm S.E.

\section{RESULTS}

Inspection of the results of the present study revealed two groups of animals which could be clearly distinguished by the magnitude of their plasma CAT responses to cord cutting, the severity of postpartum acidosis, the degree of hypothermia, and the extent of rise in plasma FFA concentrations after cord clamping. There were no differences in gestational age, birth weight, or mode of delivery that would have distinguished them beforehand. These groups are designated group I (four animals) and group II (four animals). The group I animals had significantly lower $\mathrm{pH}$ values before cord cutting and postpartum, and evidenced more severe postpartum hypothermia. After cord cutting the increments in plasma NE and $E$ levels were greater and the increase in plasma FFA concentration less than in the group II animals.

Mean fetal plasma NE and $E$ concentrations are shown in Figures 1 and 2, respectively. The effects of surgical manipulation and delivery on plasma CAT concentrations are reflected in the -60 to zero time samples. As noted, delivery evoked a significant elevation of plasma NE and E levels to 908 (737 to 1119) and 197 (181 to 214) pg/ml and 418 (214 to 506 ) and 105 (82 to 125) pg/ $\mathrm{ml}$ in groups I and II, respectively. These values returned quickly (by the -30 -min sampling) to basal levels. The plasma NE and $\mathrm{E}$ levels averaged over the subsequent observation period $(-30$ to 0 $\mathrm{min}$ ) were 353 (253 to 494) and 16 (12 to 21$) \mathrm{pg} / \mathrm{ml}$ in group I and 174 (99 to 304 ) and 12 (11 to 13$) \mathrm{pg} / \mathrm{ml}$ in group II. Group differences in postdelivery peak and subsequent nadir plasma CAT values were small. There were no differences in precord cutting E values. Group I animals, however, had higher precord cutting NE concentrations than group II $(P<0.05)$.

After umbilical cord clamping there was a dramatic rise in plasma CAT levels in both groups of animals. Plasma levels of $\mathrm{NE}$ and $\mathrm{E}$ in group I animals rose to $31,952(21,030$ to 48,548$)$ and $34,753(15,747$ to 76,699$) \mathrm{pg} / \mathrm{ml}$, respectively at $5 \mathrm{~min}$ and 7,596 $(3,482$ to 16,569$)$ and $20,000(18,491$ to $21-630) \mathrm{pg} / \mathrm{ml}$, respectively, at $15 \mathrm{~min}$. In group II animals there was a similar dramatic rise but of a significanttly lower magnitude. NE and $E$ levels at 5 $\min$ were $2,819(1,117$ to 7,114$)$ and $695(162$ to 2,982$) \mathrm{pg} / \mathrm{ml}$,

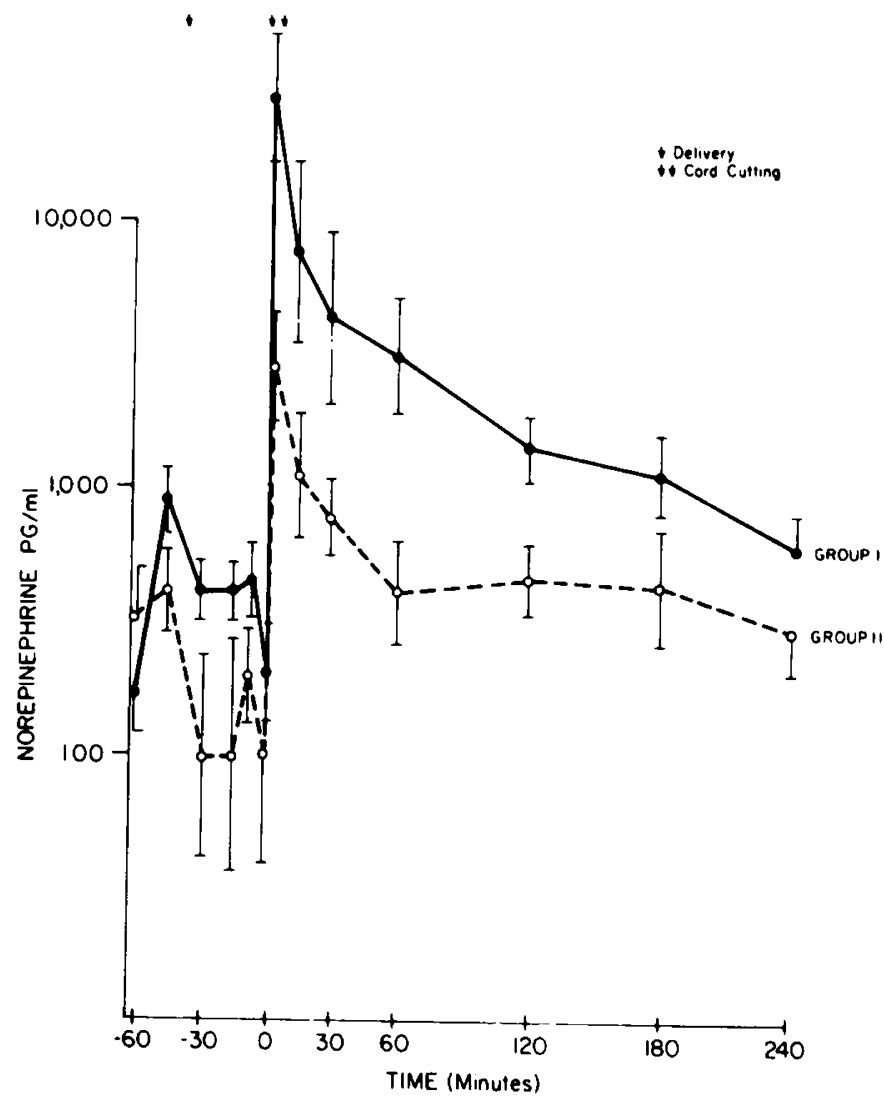

Fig. 1. Plasma norepinephrine $\mathrm{pg} / \mathrm{ml}$ in group I and II lambs during the period of study. Zero time refers to the time of umbilical cord cutting (UC). Animals were delivered (D) 35 to $45 \mathrm{~min}$ before cord cutting. Values are recorded as geometric mean and S.E. Values for groups I and II compared by two-way ANOVA during the period before $(P<0.05)$ and after cord cutting $(P<0.0001)$.

respectively, and 1,101 (369 to 3,291$)$ and $116(71$ to 191$) \mathrm{pg} / \mathrm{ml}$, respectively, at $15 \mathrm{~min}$. The differences in NE and $\mathrm{E}$ concentrations between the two groups when compared by two-way ANOVA were significant over the entire $240 \mathrm{~min}$. observation period, $P<0.0001$ and $<0.0001$, respectively.

The mean blood gas results are shown for the two groups of animals in Table 1. There was a slight but significantly lower $\mathrm{pH}$ in the group I lambs before cord clamping. There were no significant differences in blood $\mathrm{PO}_{2}$ or $\mathrm{PCO}_{2}$ values between the groups over the observation period.

The changes in plasma FFA levels observed over the study period are summarized in Figure 3. Group I lambs had a later, more attenuated rise in FFA than the group II animals; this difference which was significant $(P<0.001)$ persisted over the entire postcord cutting period. The blunted FFA response in the group I animals correlated with a more marked post cordcutting hypothermia; this is evident from the time courses of the temperature responses of the two groups. The nadir in body temperature in the group I animals $\left(32.5^{\circ} \mathrm{C}\right)$ was lower than that in group II $\left(36^{\circ} \mathrm{C}\right)$ (Fig. 4). Moreover, the group II animals regained body temperature sooner. These differences compared over the $240-\mathrm{min}$ observation period were significant by two-way ANOVA $(P<$ $0.01)$.

The nature of the CAT response was investigated by comparing the ratios of plasma $N E$ and $E$ concentrations at various time points in the two groups of animals. The plasma NE/E ratio data are shown in Table 2 . The base line ratios are similar. In the group $I$ animals there was a striking reduction in the $N E / E$ ratio at 5 and 15 min such that $\mathrm{E}$ was the predominant plasma CAT. A similar trend was noted in the group II animals; however, no reversal of the NE/E ratio was observed. 


\section{DISCUSSION}

In earlier studies of sympatho-adrenal activity in response to parturition it has not been possible to differentiate the effects of labor, intrapartum asphyxia, delivery, and cord clamping on CAT release. In the present study we observed a minimal CAT response coincident with the operative procedures and/or delivery from the uterus. This was transient, and within 30 min plasma CAT levels returned to base line values comparable to basal nonstressed fetal concentrations reported earlier from our laboratory (12). Subsequent umbilical cord clamping was observed to evoke a rapid and

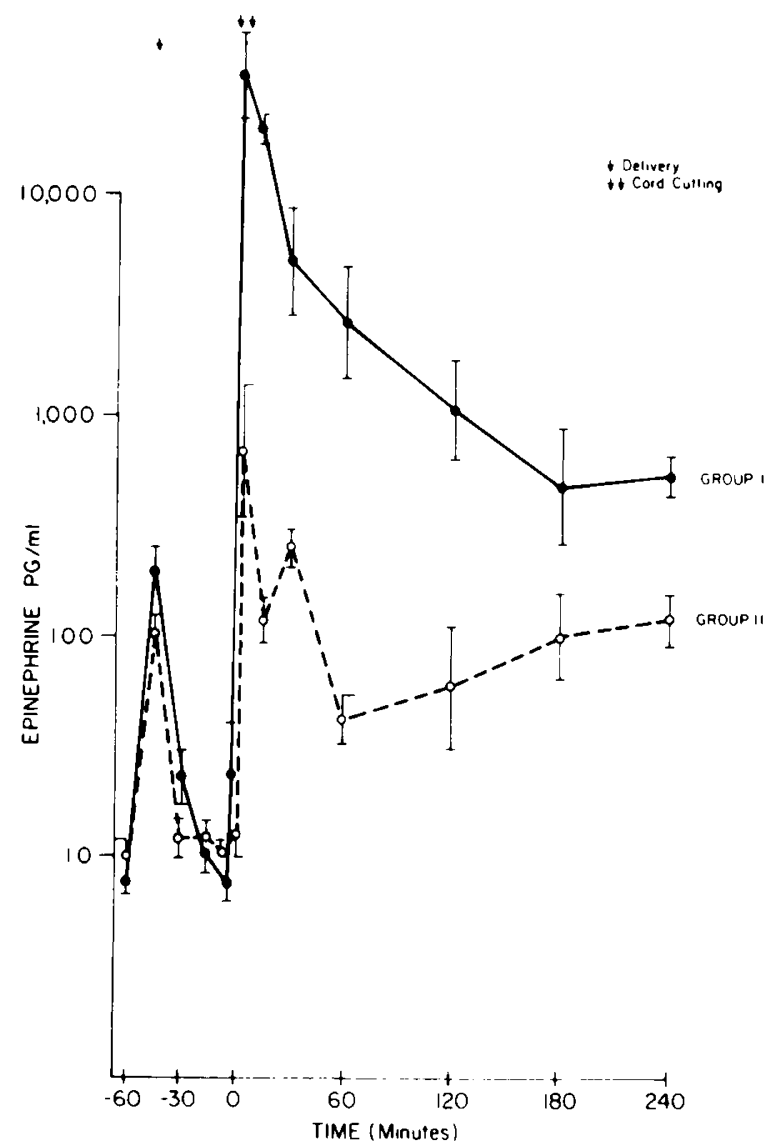

Fig. 2. Plasma epinephrine $\mathrm{pg} / \mathrm{ml}$ in group I and II lambs during the period of study. Zero time refers to the time of umbilical cord cutting $(U C)$. Animals were delivered $(D) 35$ to $45 \mathrm{~min}$ before cord cutting. Values are recorded as geometric mean and S.E. Values for groups $I$ and II compared by two-way ANOVA during the period before (not significant) and after cord cutting $(P<0.0001)$.

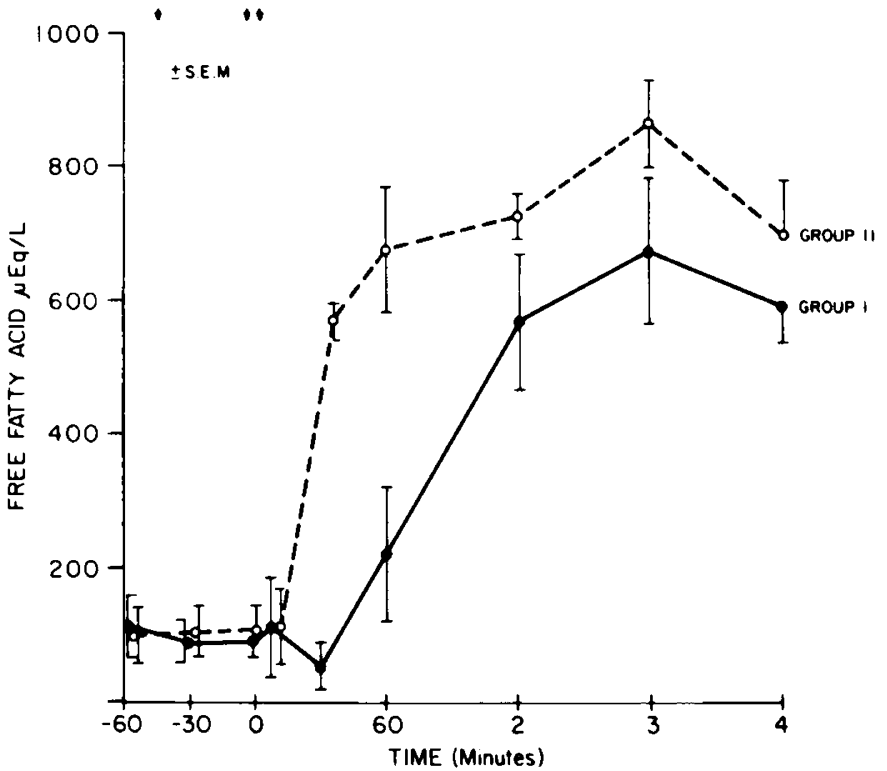

Fig. 3. Plasma free fatty acid (equivalents/liter) in group I and II lambs during the period of study. Zero time refers to the time of umbilical cord cutting $(U C)$. Values are recorded as mean and S.E. Values for groups I and II compared by two-way ANOVA after cord cutting $(P<0.001)$.

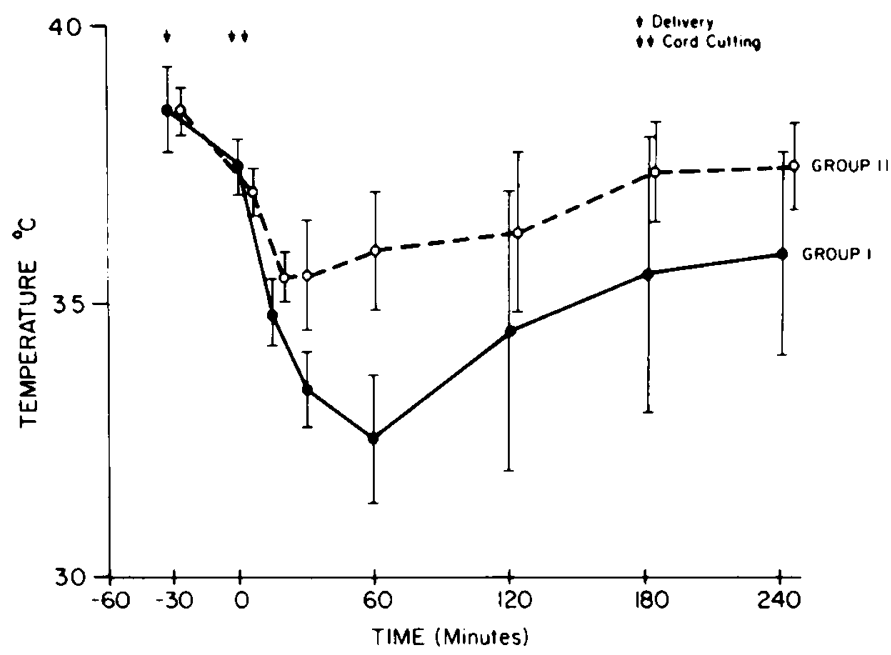

Fig. 4. Rectal temperature $\left({ }^{\circ} \mathrm{C}\right)$ in group I and II lambs during the period of study. Zero time refers to the time of umbilical cord cutting $(U C)$. Values are recorded as mean and S.E. Values for groups I and II compared by two-way ANOVA after cord cutting $(P<0.01)$.

Table 1. Blood gas values in group I and II lambs

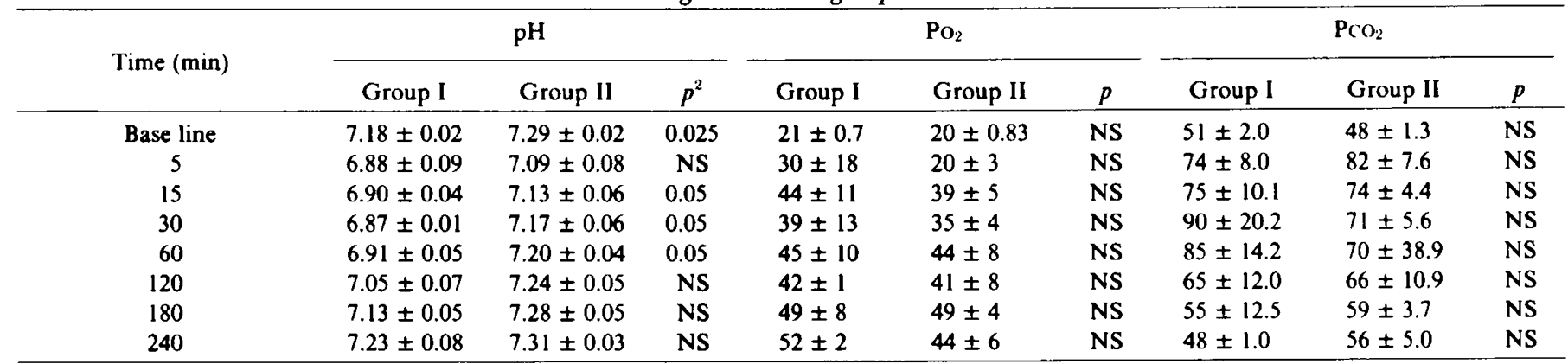

\footnotetext{
' Each group included 4 animal preparations. All values are recorded as mean \pm S.E.

${ }^{2}$ Not significant.
} 
Table 2. Mean fetal and newborn $N E / E$ ratios before and after umbilical cord cutting

\begin{tabular}{ccc}
\hline Time (min) & Group I $^{1}$ & Group II' $^{\prime}$ \\
\hline-30 & 23 & 71 \\
-15 & & \\
-5 & 19 & 44 \\
0 & 0.7 & 3 \\
5 & 1.0 & 18 \\
15 & 1.6 & 11 \\
30 & 1.1 & 24 \\
60 & 1.1 & 14 \\
2 & 1.7 & 7 \\
3 & 1.8 & 6 \\
4 & & \\
\hline
\end{tabular}

'Four animals.

marked increase of both plasma NE and E levels, presumably through sudden discharge of the neurosympathetic system.

Our study animals could be separated into two distinct groups on the basis of the observed CAT responses, the severity of postpartum acidosis, the extent of subsequent FFA mobilization, and the degree of postpartum hypothermia. There were significant differences between groups for each of these criteria. Group I animals showed a more striking elevation in CAT and yet blunted FFA and thermogenic responses. Blood $\mathrm{Po}_{2}$ values, however, were not different in the two groups of animals at any period of sampling, whereas $\mathrm{pH}$ values were significantly lower in group I animals before and after umbilical cord cutting.

The precise stimulus for the observed CAT response to cord cutting is not entirely clear. Dawes (11) suggested that several stimuli (thermal, proprioceptive, baroreceptors, etc.) operating through central processes evoke a generalized neurosympathetic discharge at the time of birth. In a previous study designed to dissociate the influence of neonatal cooling and cord cutting on triiodothyronine (T3) release, delayed cord cutting produced marked hypothermia; however the increases in serum FFA and T3 concentrations were not observed until the cord was cut (12). Those observations suggested that the CAT release responsible for the profound increases T3 and FFA did not occur, despite hypothermia, until cord cutting. Since return to baseline concentration of plasma CAT was observed during the period before cord cutting in this study, thermal, tactile, and proprioceptive stimuli were dissociated from cord cutting as signals for the CAT release observed. These results suggest, therefore, that umbilical cord cutting itself significantly augments circulating CAT at birth. The umbilical cord lacks innervation so that neurally mediated effects of mechanical stimulation of the umbilical cord is unlikely. Purves and Briscoe (26) observed that when the cord is clamped there is a marked increase in postganglionic activity in the cervical sympathetic nerves and a comparable increase in chemoreceptor activity. Sudden, marked changes in total peripheral resistance and stimulation of baroreceptor activity are likely important mechanisms for the initiation of this reflex.

Plasma CAT represents leakage from the sympathetic nervous system as well as secretion from chromaffin tissues of adrenal medullary and extramedullary origin. Secretion from the adrenal medulla can be neurally induced or stimulated directly in response to hypoxia. The latter evokes a predominant NE response while the nature of the neurally mediated response depends on the degree of fetal development. As term gestation is approached the proportion of $E$ in the adrenal medulla increases (9). Similarly the magnitude of the nervous component of fetal adrenal CAT discharge and the proportion of $E$ released in response to stress increase near term. In fact, in the sheep fetus the adrenal medulla appears to be virtually unresponsive to nerve stimulation until the last 20 days of fetal life. There is then a very rapid increase in CAT secretion and an increase in the proportion of E released (7).

The striking differences in the NE/E ratios in our two groups of animals suggest a larger, neurally mediated adrenal medullary release of $\mathrm{E}$ in the group I animals. Previous observations in the acutely exteriorized fetal lamb suggested that hypoxia was more potent than acidosis as a stimulus for CAT release (8). These observations were, however, conducted in relatively immature animals (115 to 130 days). Our results demonstrate acidosis in mature animals is capable of markedly augmenting CAT release presumably through increased neurosympathetic efferent activity. This may be due to altered chemoreceptor sensitivity which follows cord clamping (26).

The present studies have demonstrated the importance of this CAT response to extrauterine nonshivering thermogenesis manifest both as FFA release and maintenance of body temperature. The FFA concentrations observed and their potential importance in neonatal adaptation is similar to the previous observations of Van Duyne et al. (31). The importance of the post cord clamping neurosympathetic discharge for postnatal carbohydrate homeostasis has been studied $(30,17)$. In the chronically catheterized ovine fetus at term, glucagon release and inhibition of insulin release were noted in response to $E$ infusion and these effects could be blocked by propranolol and stimulated by cord cutting. Thus, the neonatal CAT surge probably both directly and by increasing the glucagon/insulin secretion ratio stimulates glycogenolysis and gluconeogenesis and increases hepatic glucose output.

Recent work suggests a role for adrenergic mechanisms in the release of pulmonary surfactant at birth $(0,14,33)$, in inhibition of tracheal fluid production rate $(3,22,32)$ and in surfactant synthesis (20). Ontogeny of $\beta$-adrenergic receptors in lung homogenates and an acceleration of this maturational phenomenon in response to maternal glucocorticoid administration has been recently reported (6).

The adaptive carddiovascular functions potentially subserved by the postcord clamping neurosympathetic discharge are numerous. With birth there is an increase in systemic blood pressure, a drop in pulmonary vascular resistance, closure of fetal shunts and an increase in cardiac output and cardiac work (27). Using an acutely adrenalectomized puppy, Geis et al. (16) suggested that circulating CAT plays a greater ole in the maintenance of cardiovascular homeostasis in the 2- to 14-day-old puppy than in the adult dog. While the ductus arteriosus is innervated and the isolated ductus shows a constrictor response to adrenergic agonists in vitro, $\alpha$ and $\beta$ adrenergic blockade did not block the constrictor response of the isolated ductus to increasing $\mathrm{Po}_{2}$ levels $(1,4,24)$; it is unclear, therefore, what role the neonatal CAT surge plays in regulation of the ductus arteriosus blood flow. Similarly, while there are maturing adrenergic effector mechanisms in the developing kidney(s) (5), the precise renal circulatory effects of the neonated CAT surge remain to be elucidated.

The present studies demonstrate the rapid and dramatic rise in plasma norepinephrine and epinephrine which occurs after umbilical cord cutting. The observed response is probably a reflection of a generalized increase in neurosympathetic activity and neurally mediated adrenal epinephrine release. A role for the CAT surge in FFA mobilization and chemical thermogenesis was suggested by the data and the magnitude of the response was sufficient to suggest an important role in other metabolic and cardiovascular aspects of newborn adaptation. The separate contributions of increased postganglionic neurosympathetic activity and adrenalmedullary CAT release to newborn adaptation should be explored further.

\section{REFERENCES AND NOTES}

1. Aronson, S., Jensen, G., Owman, C. H., and Sjoberg. N.O.: Innervation and contractile response of the human ductus arteriosus. Eur. J. Pharmacol.. II: 1781970.

2. Artal, R., Glatz, T., Nathanielsz, P. W., and Hobel, C.J.: The effect of maternal blood volume depletion on the release of cathecholamines in the fetal lamb and ewe. Soc. Gynecol. Invest. (Abstract), 26: 97 (1977).

3. Bergman, B., Hedner, $T$., and Lundborg, $P$.: Pressure-volume relationship and fluid content in fetal rabbit lung after $\beta$-receptor stimulating drugs. Pediatr. Res., /4: 10671980. 
4. Borius, L. O., Malmfors, T., McMurphy, D.M., and Olson, L.: Demonstration of adrenergic receptor function and innervation in the ductus arteriosus of the human fetus. Acta Physiol. Scand., 77: 3161969.

5. Buckley, N.M., Brazeau, P., Gootman, P.M., and Frasier, I.D.: Renal circulatory effects of adrenergic stimuli in anesthetized piglets and mature swine. Am. J. Physiol., 237: H690 1979.

6. Cheng, J.B., Goldfein, A., Ballard, P.L., and Roberts, J.M.: Glucocorticoids increase pulmonary $\beta$-adrenergic receptors in fetal rabbit. Endocrinology, 107; 16461980.

7. Comline, R.S., and Silver, M.: The release of adrenaline and noradrenaline from the adrenal glands of the foetal sheep. J. Physiol. (Lond.), 156: 424, 1961.

8. Comline, R.S., and Silver, M.: Factors responsible for the stimulation of the adrenal medulla during asphyxia in the fetal lamb. J. Physiol. (Lond.), 178: 21 1965.

9. Comline, R.S., and Silver, M.: Development of activity in the adrenal medulla of the foetus and newborn animal. Br. Med. Bull., 22: 161966.

10. Corbet, A.J.S., Flax, P., and Rudolph, A.J.: Role of autonomic nervous system controlling surface tension in fetal rabbit lungs. J. Appl. Physiol., 43: 1039 1977.

11. Dawes, G.S. A comparative study of the changes at birth. In: Foetal and Neonatal Physiology. (Year Book Medical Publishers, Chicago).

12. Eliot, R.J., Klein, A.H., Glatz, T.H., Lam, R., Nathanielsz, P.W., and Fisher D.A.: Norepinephrine (NE), epinephrine (E), and dopamine (DA) responses to parturition in premature and full term fetal sheep. Clin. Res., 27: 124A 1979.

13. Eliot, R.J., Lam, R., Leake, R.D., Hobel, C.J., and Fisher, D.A.: Plasma catecholamine concentrations in infants at birth and during the first $\mathbf{4 8}$ hours of life. J. Pediatr., 96: 3111980.

14. Enhorning, G., Chamberlain, D., Contreras, C., Burgoyne, R., and Robertson, B.: Isoxsuprine-induced release of pulmonary surfactant in the rabbit fetus. Am. J. Obstet. Gynecol., 129: 1971977.

15. Greenberg, R.E., and Lind, J.: Catecholamines in tissues of the human fetus Pediatrics, 277: 904 1961.

16. Geis, W.P., Tatooles, C.J., Priola, D.V., and Friedman, W.F.: Factors influencing neurohumoral control of the heart in the newborn dog. Am. J. Physiol., 228. 16851975.

17. Grajwer, L.A., Sperling, M.A., Sack, J., et al: Possible mechanisms and significance of the neonatal surge in glucagon secretion: Studies in newborn lambs. Pediatr. Res., 11: 833 1977.

18. Hobel, C.J., Artald, R., Emmanoulides, G., Lam, R.W., and Fisher, D.A. Maternal and fetal catecholamine responses to maternal exercise in the normal and comprised pregnant ewe. Soc. Gynecol. Invest. (Abstract) 26: 52 (1977).
19. Johnson, G.A., and Peuler, J.D.: Radiometric assay for plasma norepinephrine and epinephrine. Anal. Biochem., 51: 6181973

20. Kanjanapone, V., Hartig-Becken, I., and Epstein, M.F.: Effect of isoxsuprine on fetal lung surfactant in rabbits. Pediatr. Res., 14: 2781980.

21. Lagercrantz, H., and Bistoletti, P.: Catecholamine release in the newborn infan at birth. Pediatr. Res., 11: 8891973.

22. Lawson, E.E., Brown, E.B., Torday, J.S., Madansky, P.L., and Taeusch, H.W. Jr.: Influence of epinephrine on fetal pulmonary fluid production and surfactant release. Physiologist, 20: 551977.

23. Nakai, T., and Yamada, R.: The secretion of catecholamines in the newborn infant at birth. Pediatr. Res., 11: 8891973

24. Oberhansli-Weiss, I., Heymann, M.A., Rudolph, A.M., and Melmon, K.L.: The pattern and mechanisms of response to oxygen by the ductus arteriosus and umbilical artery. Pediatr. Res., 6: 6931972.

25. Passon, P.G., and Peuler, J.D.: Radiometric assay for plasma norepinephrine and epinephrine. Anal. Biochem., 51: 6181973.

26. Purves, M.J., and Briscoe, T.J.: Development of chemoreceptor activity. Br. Med. Bull. 22: 561967.

27. Rudolph, A.M.: The changes in the circulation after birth. Circulation, $41: 343$ 1970.

28. Sack, J., Beaudry, M., DeLamater, P.V., Oh, W., and Fisher, D.A.: Cord cutting triggers hypertriiodothyroninemia and nonshivering thermogenesis in the newborn lamb. Pediatr. Res., 10: 1691976.

29. Soloni, F.G., and Sardina, F.C.: Colorimetric microdetermination of free fatty acids. Clin. Chem., 19: 4191973.

30. Sperling, M.A., Christensen, R.A., Gantuli, S., and Anand R.: Adrenergic modulation of pancreatic hormone secretion in utero: studies in fetal sheep. Pediatr. Res., 14: 203 (1980)

31. Van Duyne, C.M., Parker, H.R., Havel, R.J., and Holm, L.W.: Free fatty acid metabolism in fetal and newborn sheep. Am. J. Physiol., 199: 9871960

32. Walter, D.V., and Olver, R.E.: The role of catecholamines in lung liquid absorption at birth. Pediatr. Res., 12: 2391978.

33. Wyzogrodski, I., Taeusch, H.W., Jr., and Avery, M.E.: Isoxsuprine-induced alterations of pulmonary pressure-volume relationships in premature rabbits. Am. J. Obstet. Gynecol., 119: 1107, 1974.

34. Requests for reprints should be addressed to: James F. Padbury, M.D., Fetal Maternal Research Laboratories, Building A-17, Harbor-UCLA Medical Center, Torrance, CA 90509 (USA).

35. This research was supported by NIH Grant HD 11753-03.

36. Received for publication December 16, 1980.

37. Accepted for publication April 3, 1981 